\title{
Zeranol Residue Detected by HPLC in Bovine Meat from Three Different Cities in Java Island
}

\author{
R. Widiastuti* \& Y. Anastasia \\ Indonesian Research Center for Veterinary Science \\ Jalan RE Martadinata 30, Bogor 16114, Indonesia \\ *Corresponding author: widiastuti.raphaella@gmail.com \\ (Received 17-12-2019; Revised 04-05-2020; Accepted 20-05-2020)
}

\begin{abstract}
Zeranol is one of non-steroidal hormonal growth promoters (HGP) that is still permitted to be used in some countries such as Australia, the United States, and others to increase weight gain. However, this non-steroidal HGP is not permitted in Indonesia. The use of zeranol to increase the growth of livestock can cause the occurrence of residue in livestock tissues and organs, having a great dangerous potential for human health. This study aimed to investigate the presence of zeranol residues in 105 samples of bovine meat collected from Jakarta, Surabaya, and Malang cities and analyzed by high-performance liquid chromatography (HPLC). The samples were added with the deproteinizing extractant of $0.2 \%$ metaphosphoric acid and acetonitrile $(6: 4, v / v)$, and purified using SAX SPE cartridge. Zeranol was then analyzed by HPLC using Shimp-pack VP-ODS $(4.6 \times 250 \mathrm{~mm})$ column with a mixture of acetonitrile-water $(40: 60, \mathrm{v} / \mathrm{v})$ as the mobile phase and detected on photo diode array detector at $262 \mathrm{~nm}$. The recoveries of the method of 3 different concentrations $(2,5$, and $10 \mathrm{ng} / \mathrm{g})$ of zeranol were $73.96 \%$ to $103.48 \%$. The detection limit and quantification limits were $0.54 \mathrm{ng} / \mathrm{g}$ and 1.80 $\mathrm{ng} / \mathrm{g}$, respectively. Zeranol residues were detected in $12(11.43 \%)$ out of 105 samples at the concentration of 1.67 to $33.29 \mathrm{ng} / \mathrm{g}$ and 7 among them exceeding $2.0 \mathrm{ng} / \mathrm{g}$. The results obtained in this study indicated that zeranol was still being used to increase cattle-meat production. Therefore, strict control must be implemented at all stages, from production to consumption, regarding the application of this HGP in livestock.
\end{abstract}

Keywords: bovine meat; zeranol; growth promoter; residue; HPLC

\section{INTRODUCTION}

The production of animal origin foods, especially meat and meat products, has substantially increased throughout the world to meet the increased demand. Zeranol or zearanol ( $\alpha$-zearalanol), is a synthetic nonsteroidal estrogen of the resorcylic acid lactone group produced by Fusarium species, have been used to increase the live weight gain in food animals. Because of its carcinogenic potential and endocrine-disrupting biological activity, zeranol had been banned since 1981 within the European Union (EU) and the Member States.

Zeranol is still approved to be used as a growth promoter in several countries like Australia and the USA under the trade name of RalGro ${ }^{\circledast}$ in the USA. Zeranol and its derivatives (zearalenone and taleranol) can accumulate in humans consuming food containing zeranol regularly (Bircher et al., 2015). Zeranol residues in meat consumed cause adverse effects on human health, such as disruption in human hormone balance, causing developmental problems, interfering with the reproductive system, and can even lead to the development of breast, prostate, or colon cancer (Kumar et al., 2018). Therefore, FAO/WHO through Codex Alimentarius, set the maximum residue level of zeranol is $2 \mathrm{ng} / \mathrm{g}$ in muscle and $10 \mathrm{ng} / \mathrm{g}$ in the liver (CX/MRL 2-2018, 2018). In Indonesia, zeranol residue is one of the residues which must be tested for imported livestock products entering Indonesia, based on the Decree of The Head of Agriculture Quarantine Agency Number 2464/Kpts/ KR.120/K/11/2018 (Badan Karantina Pertanian, 2018).

Zeranol residue was found in many different types of samples such as bovine meat, liver, and kidney of cattle (Mor et al., 2011, Yücel et al., 2018), chicken meat, liver and kidney of chicken (Hemmat et al., 2018), and bovine urine (Matraszek-Zuchowska et al., 2013). Fortunately, zeranol residue is not stable during storage and cooking treatment (Kukhtyn et al., 2020). Frozen temperature $\left(-18^{\circ} \mathrm{C}\right)$ for 6 months would decrease by $33.2 \%$ of the zeranol content, whereas cooking up to 60 min would decrease $32 \%$ of the zeranol content.

The development of a simple, rapid, sensitive, and specific method to detect zeranol residue in animal food products is required. Several detection methods for determination of zeranol had been reported, and most of the methods applied are high-performance liquid chromatography (HPLC) (Lee et al., 2018), enzymelinked immunosorbent assay (ELISA) (Khadijah et al., 
2015), liquid chromatography-mass spectrometry-mass spectrometry (LC-MSMS) (Matraszek-Zuchowska et al., 2013), and gas chromatography mass-spectrometry (GC-MS) (Matraszek-Zuchowska et al., 2012). Massspectrometry methods are good in specificity and sensitivity. Still, they are costly, complicated for routine clinical studies, and not available in most laboratories. In contrast, ELISA exhibits good results and rapid screening but has the main drawback of providing incorrect results occurred from cross-reactions (Yücel et al., 2012).

This study was the first investigation report in Indonesia aiming to monitor the presence of zeranol residue in bovine meat of imported (premium and nonpremium) beef meat from Jakarta, fattening beef meat from Malang, and domestic beef meat from Surabaya which were analyzed by HPLC with PDA detection. A previous study in Indonesia reported the presence of zeranol residue in imported Australian and New Zealand beef meat (Khadijah et al. ,2015) with the use of ELISA detection.

\section{MATERIALS AND METHODS}

\section{Beef Meat Collection}

In this study, a total number of one hundred and five (105) beef meat samples (approximately 100 to 250 g) were collected from three different cities (Jakarta, Malang, and Surabaya). Four types of beef meat samples collected were: (1) 5 premium beef meat samples collected from Soekarno Hatta Airport Agricultural Quarantine Centre, (2) 50 non-premium imported beef meat samples collected from Tanjung Priok Seaport Agricultural Quarantine Centre, both in Jakarta, (3) 28 fattening beef meat samples collected from a slaughterhouse in Malang City (Malang has the largest and most populated for beef cattle in East Java Province), and (4) 22 domestic beef meat samples bought from traditional and supermarkets in Surabaya.

\section{Chemicals and Reagents}

Zeranol standard was of high purity grade ( 98\%, HPLC) and was supplied by Sigma (Sigma-Aldrich, Darmstadt, Germany). Both reagents and solvents used were of analytical or HPLC grade quality and purchased from Merck (Darmstadt, Germany). Ultrapure (UP) water was generated by a water purification system of Milli Q Direct 8/16 System (Millipore SAS, 67120 Molsheim, France). Samples were purified through SAX SPE (Bond Elut LRC-SAX $500 \mathrm{mg}$, Agilent, USA). Technical nitrogen gas was produced by the nitrogen generator unit (Claind, Leino-Italy).

\section{Standard Solutions Preparation}

Zeranol stock standard solution with a concentration of $1 \mathrm{mg} / \mathrm{mL}(1000 \mu \mathrm{g} / \mathrm{mL})$ was made by diluting 25 $\mathrm{mg}$ zeranol standard powder in $25 \mathrm{~mL}$ methanol (HPLC grade) in $25 \mathrm{~mL}$ volumetric flask and put in the ultrasonic bath for $5 \mathrm{~min}$. The stock standard solution was stored in amber glass vials at $4^{\circ} \mathrm{C}$ in the absence of light. Working standard solutions were prepared weekly by diluting stock standard solutions with methanol and stored in the refrigerator.

\section{Sample Extraction and Zeranol Detection}

The extraction method was adapted from a method developed by Horie \& Nakazawa (2000). A $1 \mathrm{~g}$ fat-free beef meat sample was placed in a $50 \mathrm{~mL}$ polypropylene tube and added with $10 \mathrm{~mL}$ of the deproteinizing extractant consisted of $0.2 \%$ metaphosphoric acid and acetonitrile $(6: 4, \mathrm{v} / \mathrm{v})$, and vortexed for $2 \mathrm{~min}$. The filtrate was purified through a SAX SPE that conditioned previously with $5 \mathrm{~mL}$ of acetonitrile. After the application to the SAX column, the barrel was then rinsed using $5 \mathrm{~mL}$ of $20 \%$ acetonitrile. The zeranol was eluted with $5 \mathrm{~mL}$ of acetonitrile and the residue was evaporated under a stream of nitrogen gas at $45^{\circ} \mathrm{C}$ until dry. The residue was dissolved in $1 \mathrm{~mL}$ of $40 \%$ acetonitrile and passed through a $0.45 \mu \mathrm{m}$ PVDF syringe filter unit prior to injecting it into the HPLC. The injection volume was 20 $\mu \mathrm{L}$.

\section{Instrumentation and Chromatographic Condition}

The HPLC instrumentation used was a Shimadzu Prominence (Kyoto, Japan) consisted of LC-20AD pump and SPD-M20A photo diode array (PDA) detector. The wavelength was set at $262 \mathrm{~nm}$. The analytical separation was conducted using a reversed-phase column Shimppack VP-ODS $(4.6 \times 250 \mathrm{~mm})$ (Shimadzu), equipped with a guard column $(5 \times 4.6 \mathrm{~mm})$ containing the same packing material. The mobile phase prepared daily consisting a mixture of acetonitrile-UP water (40:60, $\mathrm{v} / \mathrm{v}$ ), filtered through a $0.45 \mu \mathrm{m}$ PVDF filter (Whatman, Maidstone, UK), and sonicated prior to use and carried isocratically (Liu et al., 2007) at a flow rate of $1 \mathrm{~mL} / \mathrm{min}$.

\section{Method Validation}

Half method validation for analysis of zeranol in beef meat was assessed in this study that was guided by ICH (2005) and FDA (2019) with the following parameters of specificity, matrix-matched calibration curve, recovery, detection limit, and quantitation limit.

Specificity. The selectivity test was performed by observing the chromatogram of zeranol standard, unfortified (blank) samples, and spiked samples.

Linearity and range. A matrix calibration curve was prepared from a series of zeranol standards at different concentrations from 5 to $20 \mathrm{ng} / \mathrm{mL}$ in the blank meat sample, and plot the peak areas versus concentration, to obtain the correlation coefficient $\left(\mathrm{r}^{2}\right)$.

Recovery and precision. The recoveries of the method were determined by fortified the zeranol standards (prior to the extraction step) into the blank meat samples at 2, 5, and $10 \mathrm{ng} / \mathrm{g}$. The accuracy of the method was determined 
by assessing the agreement between the measured and known concentrations of the fortified samples. The intraday precision of the method was determined three times on the same day by calculating the relative standard deviation (\% RSD) for the repeated measurements of zeranol.

Sensitivity. The sensitivity of the method was evaluated from the detection limit (LOD) and quantification limit (LOQ) that were obtained by adding 3 and 10 times, respectively, standard deviations of 10 blank samples analyzed to the mean blank value. The detection limit (LOD) is the concentration that provides a signal-to-noise ratio of about 3:1, while the quantification limit (LOQ) is the concentration that provides a signal-to-noise ratio of about 10:1. The calculation is mean +3.3 SD blank for the LOD, and mean + 10 SD blank for LOQ.

\section{RESULTS}

\section{Method Validation}

The first important step of this research was the selection of HPLC conditions, referring that mostly the detection method available for zeranol in meat samples was performed by LC-MS. Figures $1,2 a$, and $2 b$ are a chromatogram of zeranol standard, a chromatogram of unfortified (blank) meat sample, and a chromatogram of meat sample with positive zeranol residue, respectively. Zeranol is eluted approximately at 3.9 minutes and revealed the absence of co-eluting peaks at the retention time of zeranol interference. This result indicates that the identified peak of the analyte was pure and confirmed. All parameter studies of the half validation method are summarized in Table 1 and Table 2.

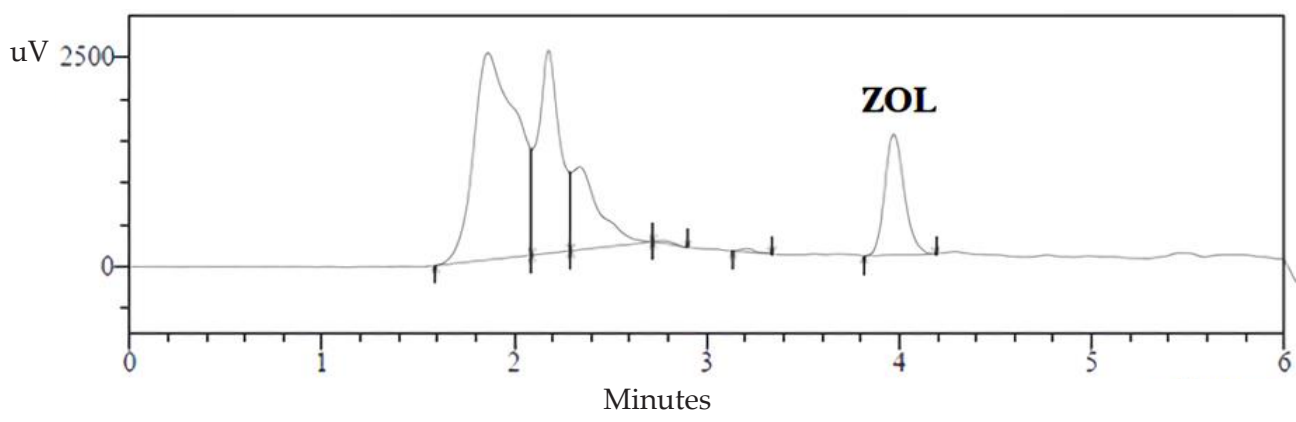

Figure 1. Chromatogram of $50 \mathrm{ng} / \mathrm{mL}$ zeranol (ZOL) standard detected using a mobile phase of acetonitrile-DI water $(40: 60, \mathrm{v} / \mathrm{v})$, at a flow rate of $1 \mathrm{~mL} / \mathrm{min}$ and a wavelength of $262 \mathrm{~nm}$.

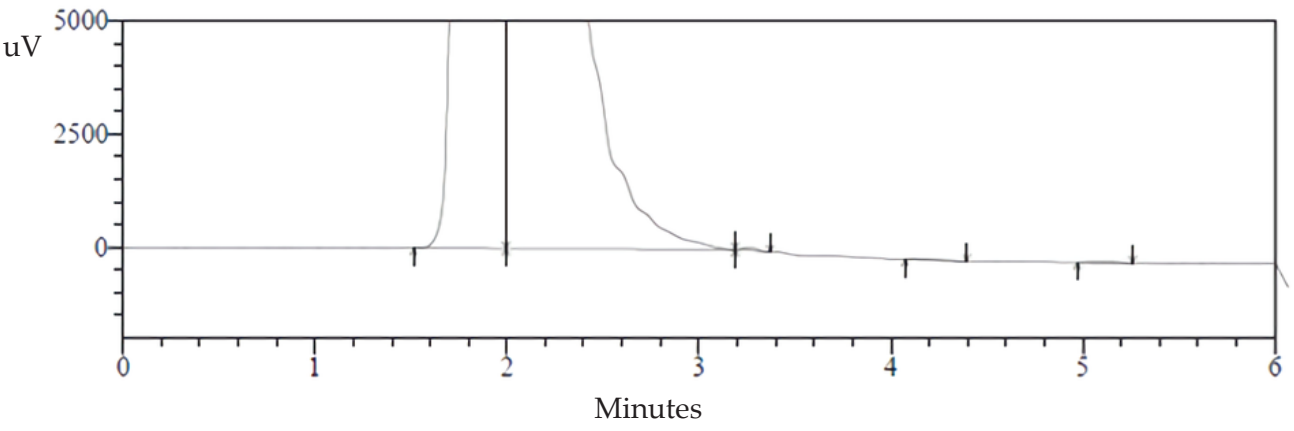

(a)

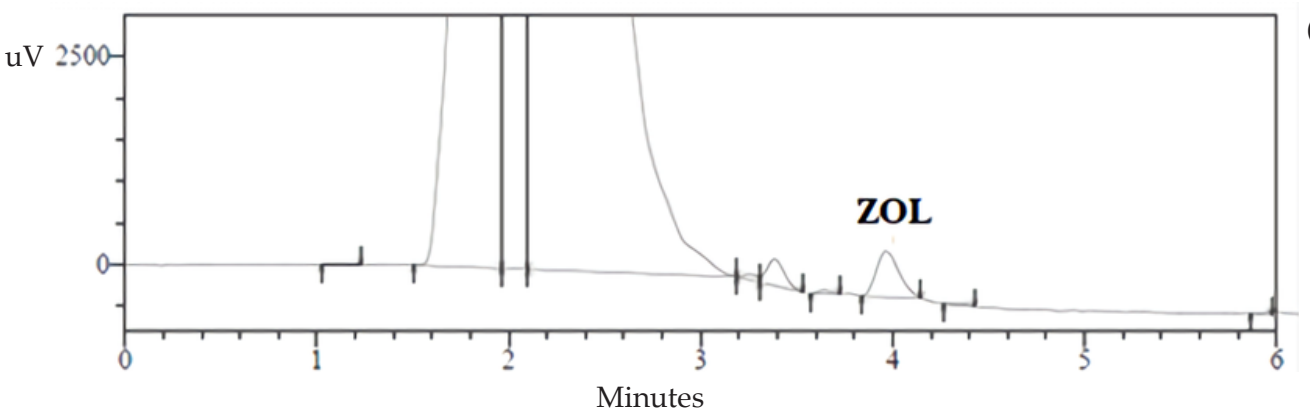

(b)

Figure 2. The chromatogram of (a) unfortified (blank) meat sample, and (b) meat sample with positive zeranol (ZOL) residue. 
Table 1. Regression and validation parameters of the HPLC method for determination of zeranol

\begin{tabular}{lc}
\hline \multicolumn{1}{c}{ Parameters } & Results \\
\hline Linearity range $(\mathrm{ng} / \mathrm{g})$ & 5 to 20 \\
Correlation coefficient $\left(\mathrm{r}^{2}\right)$ & 0.9933 \\
Recovery $(\%)$ & 73.96 to 103.48 \\
LOD (ng/g) & 0.54 \\
LOQ (ng/g) & 1.80 \\
\hline
\end{tabular}

Note: $\mathrm{LOD}=$ detection limit; $\mathrm{LOQ}=$ quantification limit.
Table 2. Precision of analytical method in detecting zeranol in beef meat

\begin{tabular}{ccc}
\hline Spike level $(\mathrm{ng} / \mathrm{g})$ & Recovery $(\%)$ & Intraday RSD $(\%)^{*}$ \\
\hline 2 & $103.48 \pm 4.31$ & 4.16 \\
5 & $73.96 \pm 11.10$ & 15.01 \\
10 & $77.51 \pm 10.26$ & 13.24 \\
\hline
\end{tabular}

Note: *Intraday RSD (relative standard deviation) $(\mathrm{n}=9)$, average of three different concentrations repeated three times within a day.

Table 3. Zeranol residues in beef meat samples collected from different locations

\begin{tabular}{clcccc}
\hline $\begin{array}{c}\text { Sampling } \\
\text { locations }\end{array}$ & \multicolumn{1}{c}{ Types of samples } & N samples & $\begin{array}{c}\text { n positive } \\
\text { samples (\%) }\end{array}$ & $\begin{array}{c}\text { Concentration } \\
\text { range (ng/g) }\end{array}$ & $\begin{array}{c}\mathrm{n} \text { sample } \\
\geq 2 \mathrm{ng} / \mathrm{g}\end{array}$ \\
\hline Jakarta & Premium imported meat & 5 & $\mathrm{ND}$ & $\mathrm{ND}$ & $\mathrm{ND}$ \\
Jakarta & Non-premium imported meat & 50 & $7(14.00)$ & $1.67-33.29$ & 2 \\
Malang & Fattening meat & 28 & $3(10.71)$ & $2.40-5.37$ & 3 \\
Surabaya & Domestic meat & 22 & $2(9.09)$ & $2.70-5.21$ & 2 \\
& Total & 105 & $12(11.43)$ & $1.67-33.29$ & 7 \\
\hline
\end{tabular}

Note: $\mathrm{ND}=$ not detected

\section{Detection of Zeranol in Meat Samples}

Table 3 summarizes the results on monitoring the occurrence of zeranol residue in this study. Zeranol was positively detected in $7(14 \%)$ out of 50 non-premium meat samples, $3(10.71 \%)$ out of 28 fattening-beef meat samples from a slaughterhouse in Malang, and 2 (9.09\%) out of 22 domestic meat samples bought in markets in Surabaya with the concentration range of $2.70-5.21 \mathrm{ng} / \mathrm{g}$. There were 7 among 105 samples having zeranol concentration above the MRL ( $2 \mathrm{ng} / \mathrm{g}$ ) and the highest level (33.29 ng/g) also was found in the meat sample from Jakarta. None of the zeranol was detected in 5 of those premium imported meat samples.

\section{DISCUSSION}

The half method validation results presented in Table 1 and Table 2 were obtained for the lowest laboratory validation level with the simplest level of validation requirements and are appropriate for confirmation within the limited application, which are achievable and repeatable. Linearity is typically demonstrated via leastsquare regression, which often judged by examining the correlation coefficient and y-intercept, and residual sum of squares. A correlation coefficient of 0.9933 met the criteria of more than 0.99 , which is generally acceptable. The mean recovery $(n=3)$ of the analytes was found by experiment to lie between $73.96 \%$ and $103.48 \%$ and meet the requirement of $70 \%-110 \%$.

The $\mathrm{C}_{18}$ non-polar sorbent reversed-phase column is the most frequently used for veterinary drug analysis, including zeranol. In this study, zeranol eluted at 3.9 minutes with the use of Shimp-pack VP ODS column $(4.6 \mathrm{~mm} \times 15 \mathrm{~mm})$ and run isocratically at a flow rate of 1 $\mathrm{mL} / \mathrm{min}$. Liu et al. (2007) applied the same mobile phase on Waters Sphrisorb® S5 ODS column $(4.6 \mathrm{~mm} \times 20 \mathrm{~mm})$, which run at a flow rate of $1.2 \mathrm{~mL} / \mathrm{min}$, and revealed that zeranol eluted at 12.2 minutes. Therefore, the results show that the HPLC method presented in this study can be considered suitable for the analytical determination of zeranol in bovine meat, owing to quick, easy to perform, having linearity in the concentration range used, and precision and adequate accuracy at the concentrations studied.

The results in Table 3 showed that the presence of zeranol residue in non-premium imported meat indicates that this substance probably might be from animals that may have been treated shortly before slaughtered in the country of origin (Australia or New Zealand) or the animals were slaughtered before reaching the withdrawal time (60-65 days) after treatment (Kart et al., 2008), and the live animals imported to Indonesia did not all go through a quarantine process (Danial et al., 2015). Whereas for fattening, positive samples indicate that those animals may have been treated shortly before shipping or after arrival in the country and slaughtered before reaching the withdrawal period.

Even though zeranol is banned from being used in Indonesia, there were 2 domestic meat samples also contaminated by zeranol, that might arise from illegal used or interconversion (see Figure 3) from feed contaminated with mycotoxin zearalenone produced by Fusarium $\mathrm{sp}$ which metabolized to zeranol and are formed naturally in urine and bile after animals consume the zearalenone (Kleinoca et al., 2002). Therefore, it is necessary to study further on the source of zeranol contamination in animal products (meat), using the appropriate methods (Matraszek-Zuchowska et al., 2012). For compliance reasons, control laboratories should be able to differentiate the presence of zeranol resulting from administration and natural exposure of zearalenone using an analytical tool such as a GCMSMS (Dusi et al., 2009).

The prevalence of the residue presence obtained in our study (detection by HPLC) of $11.43 \%$ at concentration levels of 1.67 to $33.29 \mathrm{ng} / \mathrm{g}$, showed higher preva- 

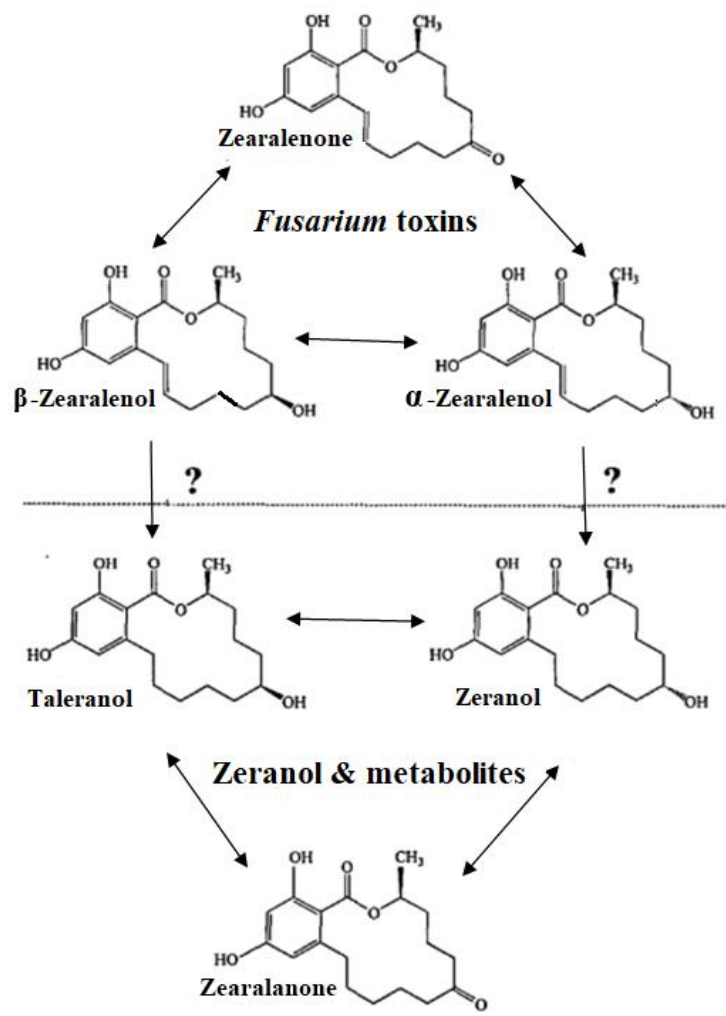

Figure 3. The possible metabolic interconversion of zeranol and its metabolites (zeranol, taleranol, and zearalanone) and the Fusarium spp. toxins (zearalenone, $\alpha$-zearalenol, and $\beta$-zearalenol) (adopted from Kennedy et al., 1998).

lence and higher contamination levels compared to the result of the previous study in Indonesia conducted by Khadijah et al. (2015) (detection by ELISA method), i.e., $5.08 \%$ at concentration levels of 0.53 to $0.92 \mathrm{ng} / \mathrm{g}$. The present results indicate the possibility of misuse of this HGP, which in the future may adversely affect human health.

For comparison, the ban of zeranol in Europe did not mean the absence of zeranol in beef meat samples analyzed. Mor et al. (2011) detected zeranol in 11 out of 30 samples collected from a slaughterhouse in Burdur (Turkey) at concentration levels of 100 to $500 \mathrm{ng} / \mathrm{g}$. Şevik \& Ayaz (2017) found zeranol residue at the levels of $0.10,0.09$, and $0.61 \mathrm{ng} / \mathrm{g}$ among 200 cattle meat samples from the butchers and supermarket in Kocaeli, Turkey. Yücel et al. (2018) detected zeranol in 24 among 80 cattle meat samples within the concentration range of 0.30 $0.50 \mathrm{ng} / \mathrm{g}$, with the highest concentration of $1.81 \mathrm{ng} / \mathrm{g}$ and noticed that the highest values were found to be that of September and October and Kukhtyn et al. (2020) still found zeranol residue on $29.8 \%$ of beef samples collected from meat processing enterprises of the Western region in Ukraine. On the other hand, Salata (2018) nor Cayci et al. (2019) did not detect zeranol residue in cattle meat.

\section{CONCLUSION}

Zeranol residue had been detected in 12 (11.43\%) samples (non-premium and domestic beef samples) at the concentration of 1.67 to $33.29 \mathrm{ng} / \mathrm{g}$ among 105 bovine meat samples that were analyzed by HPLC. There were 7 samples among them had the concentrations above the MRL of $2 \mathrm{ng} / \mathrm{g}$. The results obtained in this study indicate zeranol was still being used to increase meat cattle production. Therefore, strict control must be implemented at all stages from production to consumption, regarding the application of this HGP in livestock.

\section{CONFLICT OF INTEREST}

The Authors declare that there is no conflict of interest with any financial, personal, or other relationships with other people or organizations related to the material discussed in the manuscript. Both authors have also contributed equally.

\section{ACKNOWLEDGEMENT}

We would like to acknowledge the invaluable thank to the Ministry of Agriculture through the Indonesian Agency for Agricultural Research and Development, for supporting this study by the Indonesian Research Center for Veterinary Science (IRCVS) for funding this study. This work was conducted with the permissions and help form the staffs from Soekarno-Hatta Agricultural Quarantine Center and Tanjung Priok Agricultural Quarantine Center, the Head of Livestock Services in Malang and Surabaya City. Part of this article had been displayed at the Eighth International Symposium on Hormone and Veterinary Drug Residue Analysis, Ghent, Belgium, 22-25 May 2018.

\section{REFERENCES}

Badan Karantina Pertanian. 2018. Keputusan Kepala Badan Karantina Pertanian Nomor 2464/Kpts/KR.120/K/11/2018 Tentang Pedoman Monitoring terhadap Bahan Asal Hewan dan Hasil Bahan asal Hewan. Kementerian Pertanian Republik Indonesia, Jakarta.

Bircher, S., M.L. Card, G. Zhai, Y.P. Chin, \& J.L. Schnoor. 2015. Sorption, uptake, and biotransformation of $17 \beta$-estradiol, $17 \alpha$-ethinylestradiol, zeranol, and trenbolone acetate by hybrid poplar. Environ. Toxicol. Chem. 34: 2906-2913. https://doi.org/10.1002/etc.3166

CAC. 2014. Codex Alimentarius Commission, Procedural Manual: Principles for the Establishment of Codex Methods of Analysis. Accessed 10/12/2019. http://www. fao.org/3/a-i3243e.pdf

CX/MRL 2-2018. 2018. Maximum residue limits (MRLs) and risk management recommendations (RMRS) for residues of veterinary drugs in foods. Downloaded from www. codex-alimentarius.org

Cayci M., A.S. Kilic, H.H. Oruc, \& R. Sariyev. 2019. Screening of veterinary growth-promoting agent and antibacterial residues in beef cattle and broiler meats consumed in Bursa, Turkey. J. Res. Vet. Med. 38: 52-58.

Danial, R., H. Latief, \& A. Indrawati. 2015. Deteksi residu hormon trenbolon asetat pada sapi siap potong impor asal Australia. Acta Veterinaria Indonesiana 3: 70-76. https:// doi.org/10.29244/avi.3.2.70-76

Dusi, G., E. Bozzini, W. Assini, N. Tognoli, M. Gasparini, \& E. Ferretti. 2009. Confirmatory method for the determination of resorcylic acid lactones in urine sample using immunoaffinity cleanup and liquid chromatography-tandem 
mass spectrometry. Anal. Chim. Acta. 637: 47-54. https:// doi.org/10.1016/j.aca.2008.11.047

FDA. 2019. Guidelines for the Validation of Chemical Methods in Food, Feed, Cosmetics, and Veterinary Products. FDA Food Program. $3^{\text {rd }}$ Edition. Accessed 10/12/2019. https:// www.fda.gov/media/81810/download

Horie, M. \& H. Nakazawa. 2000. Determination of trenbolone and zeranol in bovine muscle and liver by liquid chromatography-electrospray mass spectrometry. J. Chromatogr. A. 882: 53-62. https://doi.org/10.1016/ S0021-9673(00)00205-3

Hemmat, M.I., A.A. Reham, M.D. Omaima, \& E.H. Asmaa. 2018. Survey on some hormonal residues in chicken meat, liver and kidneys. Benha Vet. Med. J. 34: 23-30. https://doi. org/10.21608/bvmj.2018.29409

Kart, A., M. Elmali, K. Yapar, \& H. Yaman. 2008. Occurrence of zeranol in ground beef produced in Kars, Turkey. J. Anim. Vet. Adv. 7: 630-632

Kennedy, D.G., S.A. Hewitt, J.D. McEvoy, J.W. Currie, A. Cannavan, W.J. Blanchflower, \& C.T. Elliot. 1998. Zeranol is formed from Fusarium spp. toxins in cattle in vivo. Food Addit. Contam. 15: 393-400. https://doi. org/10.1080/02652039809374658

Khadijah, S., H. Latif, \& A.W. Sanjaya. 2015. Residu zeranol dalam daging sapi yang diimpor dari Australia dan Selandia Baru melalui Pelabuhan Tanjung Priok. J. Veteriner. 16: 592-598. https://doi.org/10.19087/jveteriner.2015.16.4.592

Kleinoca, M., P. Zollner, H. Kahlbacher, W. Hochsteiner, \& W. Lindner. 2002. Metabolic of the mycotoxin zearalenon and the growth promoter zeranol $\mathrm{n}$ urine, liver and muscle of heifers. J. Agric. Food Chem. 50: 4769-4776. https://doi. org/10.1021/jf020160p

Kumar, V.S., C. Rajan, P. Divya, \& S. Sasikumar, S. 2018. Adverse effect consumer's health caused by hormones administered in cattle. Int. Food Res. J. 25: 1-10

Kukhtyn, M., V. Salata, R. Pelenyo, V. Selskyi, Y. Horiuk, N. Boltyk, L. Ulko, \& V. Dobrovolsky. 2020. Investigation of zeranol in beef of Ukrainian production and its reduction with various technological processing. Potravinarstvo Slovak Journal of Food Sciences 14: 95-100. https://doi. org/10.5219/1224
Lee, H.C., C.M. Chen, J.T. Wei, \& H.Y. Chiu. 2018. Analysis of veterinary drug residue monitoring results for commercial livestock products in Taiwan between 2011 and 2015. J. Food Drug Anal. 26: 565-571. https://doi.org/10.1016/j. jfda.2017.06.008

Liu, Y., C.Z. Zhang, X.Y. Yu, Z.Y. Zhang, X. Zhang, R.R. Liu, X.J. Liu, \& Z.M. Gong. 2007. Development and evaluation of immunoassay for zeranol in bovine urine. J. Zhejiang Univ. Sci. B. 8: 900-905. https://doi.org/10.1631/jzus.2007. B0900

Matraszek-Zuchowska, I., B. Wozniak, \& J. Zmudzki. 2012. Determination zeranol and its metabolites in bovine muscle tissue with gas chromatography-mass spectrophotometry. Bull. Vet. Inst. Pulawy. 56: 335-342. https://doi. org/10.2478/v10213-012-0059-4

Matraszek-Zuchowska, I., B. Wozniak \& J. Zmudzki. 2013. Determination of zeranol, taleranol, zearalanone, $\alpha$-zearalenol, $\beta$-zearalenol and zearalenone in urine by LCMS/MS. Food Additives \& Contaminants: Part A. 30: 987994. https://doi.org/10.1080/19440049.2013.787656

Mor, F., F. Şahindokuyucu, K. Kav, \& A. Köker. 2011. Determination of zeranol and trenbolone residues in tissue samples of cattle. Eurasian J. Vet. Sci. 27: 235-240.

Salata, V. 2018. The problem of control of zeranol - a growth promoter of ruminant in beef. Scientific Messenger of LNU of Veterinary Medicine and Biotechnologies. 20: 53-55. https://doi.org/10.32718/nvlvet8809

Şevik, S.E. \& N. D. Ayaz. 2017. Investigation of hormone residues in beef. Vet. Hekim Der. Derg. 88: 13-20.

van Bennekom, E.O., L. E.H.M. Brouwer, H. L. Hooijerink, \& M.W.F. Nielen. 2002. Confirmatory analysis method for zeranol, its metabolites and related mycotoxins in urine by liquid chromatography-negative ion electrospray tandem mass spectrometry. Anal. Chim. Acta. 473: 151-160. https:// doi.org/10.1016/S0003-2670(02)00975-3

Yücel, U.M., N. Atasoy, O. Ö. İşleyici, \& I. Türel. 2018. Determination of some anabolic hormone residues in cattle meat consumption in Van, Turkey. Int. J. Adv. Res. Int. 6: 129-139. https://doi.org/10.21474/IJAR01/7499 